\title{
Male patient with metastatic stage IV breast cancer achieves complete remission on second line Abemaciclib, Fulvestrant and Leuprolide: A case report
}

\author{
DAMIEN HANSRA, SHIRELLE JACKSON, JUDY SEQUEIRA \\ RAJENDRA VAZIRANI and RICARDO ALVAREZ \\ Cancer Treatment Centers of America, Breast Cancer Institute, Atlanta, GA 30265, USA \\ Received April 28, 2019; Accepted October 8, 2019
}

DOI: 10 10.3892/mco.2019.1955

\begin{abstract}
Male breast cancer occurs rarely, comprising $<1 \%$ of breast cancers. Due to the low incidence of male breast cancer, clinical trials of this disease are lacking. Therefore, therapeutic strategies utilized in the management of female breast cancer are often applied to male patients with breast cancer. Specifically, clinical outcomes using CDK 4/6 inhibitors require further investigation in male patients. To the best of our knowledge, the present report presents the first known case of a male patient treated with second line Abemaciclib, Lupron and Fulvestrant, producing complete remission. To the best of our knowledge this is also the first report of complete remission in a male breast cancer patient with a regimen utilizing a CDK 4/6 inhibitor.
\end{abstract}

\section{Introduction}

Male breast cancer is a rare entity that shares many overlapping features with female breast cancer (1). Although female breast cancer has been extensively studied, far less is known about male breast cancer. As with women, the incidence of breast cancer in men increases with age and males are typically diagnosed 5 to 10 years later than females (2-8). Furthermore, the incidence of male breast cancer seems to be increasing (9). Family history of breast cancer appears to play an important role in the development of male breast cancer (10). For example, men with a family history of breast cancer in a female or male relative have two to three times the risk of developing breast cancer themselves (11-13). BRCA2 mutations are well described as causal factors for male breast cancer. Multiple studies have demonstrated that

Correspondence to: Dr Damien Hansra, Cancer Treatment Centers of America, Breast Cancer Institute, 600 Celebrate Life Parkway, Newnan, Atlanta, GA 30265, USA

E-mail: damien.hansra@ctca-hope.com

Key words: male breast cancer, CDK 4/6 inhibitor, fulvestrant, abemaciclib, metastatic disease
$4-15 \%$ of men with breast cancer carry deleterious BRCA2 mutations (14-16). BRCA1 mutations are less commonly seen with $<5 \%$ of male breast cancer patients harboring the mutation (14,16-18). Other genes have also been implicated in male breast cancer risk including mutations in PTEN tumor suppressor gene (Cowden syndrome), TP53 (Li-Fraumeni syndrome), PALB2, and mismatch repair genes (Lynch syndrome) (19-21). Other risk factors for male breast cancer include androgen/estrogen imbalance and environmental exposures (10). Histologically, 85-90\% of males present with invasive ductal carcinomas $(22,23)$. Since males lack acini and lobules in the normal male breast lobular carcinoma is rare in male breast cancer $(9,24)$. Other histologic variants are rare but have been observed (25). Over $80 \%$ of male breast cancer is hormone positive with some series showing estrogen (ER) positivity as high as $99 \%(10,23)$. Rates of human epidermal growth factor receptor (HER2) overexpression in male breast cancer have been variable in different studies ranging from 2 to $45 \%$ (26-30). Cardoso et al (23) conducted immunohistochemistry evaluations of male breast cancer patients and found 42\% luminal A-like, $42 \%$ luminal B-like, $8.7 \%$ HER 2 positive, and $0.3 \%$ triple negative expression amog male breast cancer patients.

Prospective randomized trials in the treatment of male breast cancer are lacking due to the rarity of this entity. Furthermore, little data exists on the activity of CDK $4 / 6$ inhibitors in the treatment of hormone positive metastatic breast cancer in male patients. In this report we describe the first known case of a male patient treated with second line Abemaciclib, Lupron, and Fulvestrant producing a dramatic and durable complete remission. This is the first known case of a male achieving complete remission on a CDK 4/6 inhibitor.

\section{Case report}

We present a case of a 39 year old male with no past medical history who initially palpated a mass in his left breast in March 2015. A diagnostic mammogram and left breast ultrasound showed an irregular mass measuring 9x7x7 mm in the outer left breast at 3 o'clock suspicious for malignancy. In March 2015 he underwent left mastectomy with pathology demonstrating grade II infiltrating ductal carcinoma, $1.6 \mathrm{~cm}$ 
tumor with extensive lymphovascular invasion, five of five lymph nodes positively involved, and margins negative. The invasive component was estrogen receptor $58 \%$ positive, progesterone receptor $7 \%$ positive, human epidermal growth factor receptor 1+ not overexpressed/negative (Fig. 1). Of note, a computed tomography scan (CT) of the chest abdomen pelvis and a bone scan were performed and negative for metastatic disease. The patient was staged as pT1cN2aMx stage IIIA. He was treated with adjuvant chemotherapy with Adriamycin and Cyclophosphamide followed by Paclitaxel then radiation therapy to the chest wall and regional lymphatics (left supraclavicular fossa 5,000 cGy, left chest wall 5,000 cGy, left scar boost 1,000 cGy) ending December 2015. In December 2015 the patient was started on Tamoxifen $20 \mathrm{mg}$ orally daily and was doing well until a restaging MRI in April 2017 identified a solitary metastatic lesion to the sternum. No biopsy was performed at this time. He received palliative radiation $(4,000 \mathrm{cGy})$ to the sternal lesion which was completed in June 2017. A follow-up CT chest abdomen and pelvis October 2017 showed numerous bilateral pulmonary nodules suspicious for metastatic disease. His local team switched him to Anastrazole in June 2017. Patient presented for initial consultation to our facility October 2017 where a biopsy to confirm metastatic disease and to obtain genomic information was requested. Patient underwent video assisted thoracoscopy and wedge resection of two pulmonary nodules in left upper and lower lobes November 2017. Pathology was consistent with metastatic adenocarcinoma compatible with breast primary (Fig. 2). Genomic testing on the lung biopsy specimen revealed PIK3CA amplification, GATA 3 mutation, stable microsatellites, and a low tumor mutational burden. Genetic testing revealed absence of deleterious mutations for the BRCA1 or BRCA2 genes. In November 2017 a baseline 18F-fluorodeoxyglucose-positron emission tomography computed tomography (FDG-PET CT) was performed post wedge resection showing metastatic disease to subcarinal lymph node, left hilum, and osseous metastatic disease involving the 5 th cervical vertebral body, 2 nd lumbar vertebral body, the ninth right rib (Fig. 3). Baseline labs: CA 15-3 was 45.2 U/ml (0.0-35.0 U/ml), CA 27.29 was $60 \mathrm{U} / \mathrm{ml}(<38 \mathrm{U} / \mathrm{ml})$, complete blood count with white blood cell (wbc) count $5.2 \mathrm{~K} / \mu 1$, hemoglobin $17.2 \mathrm{~g} / \mathrm{dl}$, platelet count $134 \mathrm{~K} / \mu \mathrm{l}(150-450 \mathrm{~K} / \mu \mathrm{l})$, absolute neutrophil $2.15 \mathrm{~K} / \mu 1$, complete metabolic panel was normal except for elevated aspartate aminotransferase (AST) $69 \mathrm{U} / 1$ (17-59 U/1), alanine aminotransferase $135 \mathrm{U} / 1$ (21-72 U/1), and testosterone level 1,240 ng/dl (132-813.0 ng/dl).

The patient was initiated on Abemaciclib $150 \mathrm{mg}$ orally twice daily, Fulvestrant $500 \mathrm{mg}$ intramuscular injection days $1,15,29$ then monthly there after, and Leuprolide $7.5 \mathrm{mg}$ intramuscular injections every month in November 2017. Additionally, he was given Denosumab $120 \mathrm{mg}$ subcutaneously every month for prevention of skeletal related events. The patient tolerated treatment well with grade 1 fatigue, grade 1 hot flashes, grade 3 diarrhea mitigated by Loperamide and resolved. Testosterone levels appropriately suppressed $<50 \mathrm{ng} / \mathrm{dl}$. Patient also had transient grade 2 thrombocytopenia which resolved spontaneously and persistent grade 2 neutropenia. Follow-up PET CT February 2018 showed resolution of the hypermetabolic osseous metastatic foci with sclerosis at prior locations also there was resolution of the previously described abnormal metabolic activity in the left hilar and subcarinal mediastinal regions. Patient's subsequent PET CT imaging every 3 months remained negative with last PET CT June 2019. Patients tumor markers normalized in December 2017 with episodic mild flare up in CA 27.29. Last tumor markers over past 10 months remained negative June 2019. Patient is clinically asymptomatic and developed a grade 3 neutropenia in October 2018 requiring dose reduction of Abemaciclib to $100 \mathrm{mg}$ po BID. So far the patient remains in a durable complete remission for 18 months on this treatment regimen.

\section{Discussion}

Due to the rarity of male breast cancer, treatment approaches used for female breast cancer patients in the metastatic setting are often applied to males with metastatic breast cancer. Given that most males with metastatic breast cancer are hormone positive, hormonal therapy is often the first approach in the absence of visceral crisis (31). Tamoxifen is considered standard of care frontline therapy for males with metastatic disease $(32,33)$. Luteinizing hormones-releasing hormone agonists with or without anti-androgens have been shown to be effective in male breast cancer (34-36). Aromatase inhibitors have shown clinical activity in male breast cancer with increased clinical benefit observed with the addition of a GnRH analogue (37). Data regarding the role of Fulvestrant are limited. One pooled analysis of 23 male patients receiving Fulvestrant in the first, second, or third line setting reported a partial response rate of $26 \%$ and an additional $48 \%$ had stable disease (38). Resistance to hormonal therapy in the metastatic setting is common and most patients will eventually experience progression of disease (39). Research into the mechanisms of resistance to endocrine therapy had shed light on cell cycle regulation, particularly the cyclin-dependent kinases (CDKs). The CDKs play an important role in regulating cell-cycle progression (40).

The cyclin-dependent kinases, CDK4 and CDK6, are responsible for regulating the cell cycle by initiating the transition of cells through the G1 restriction point (41). A common feature in human cancers is the dysregulation and aberrant activation of CDK4 and 6 therefore promoting cell cycle progression $(42,43)$. Inhibition of CDK4 and CDK6 seems like a rational therapeutic target to prevent the progression of tumor cells through the G1 restriction point. Various preclinical studies have been conducted and support CDK4 and CDK6 as potential tumor targets $(22,44-46)$. Subsequently three CDK4/6 inhibitors have been approved for use in patients with metastatic breast cancer in the first or second line setting: Palbociclib (PD-0332991; Pfizer), Ribociclib (LEE011; Novartis), and Abemaciclib (LY2835219; Lilly). Palbociclib was the first FDA approved CDK 4/6 inhibitor in combination with Letrozole as initial therapy for postmenopausal women with advanced hormone positive, HER 2 negative metastatic breast cancer based on the results from the phase II PALOMA-I clinical trial (47). In PALOMA-I, patients who received Palbociclib and Letrozole experienced a roughly doubling of the progression free survival compared to treatment with Letrozole alone (47). These results were later confirmed in the randomized phase III study PALOMA-II(48). In the second line 
A

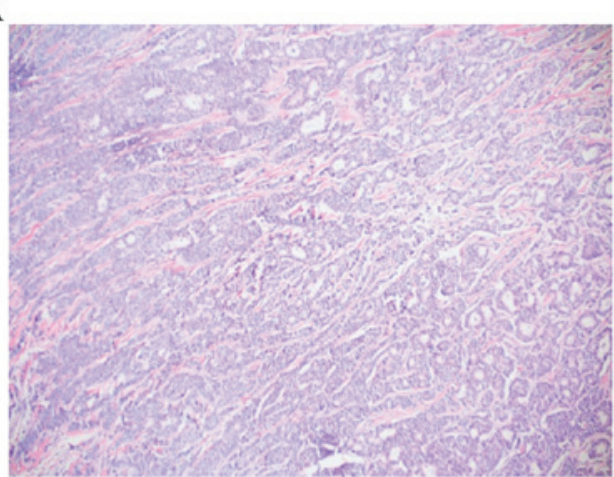

B

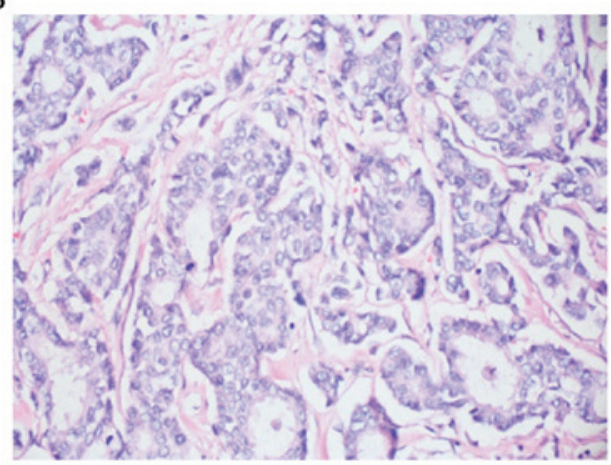

Figure 1. Invasive ductal carcinoma. (A) A combination of tubules and solid ribbons are observed under a $4 \mathrm{X}$ objective (final magnification, $\mathrm{x} 40$ ). (B) Under a $20 \mathrm{X}$ objective, nuclear pleomorphism is demonstrated, with one case of mitosis (final magnification, $x 200$ ). The overall grade was determined to be $2 / 3$.

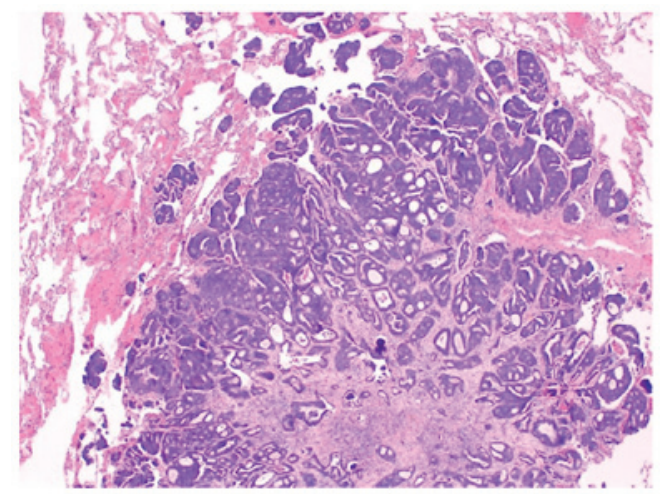

Figure 2. Invasive ductal carcinoma obtained via lung wedge resection conducted in 2017. The tumor fills $4 / 5$ of the photographed field and exhibits tumor replacing lung tissue, with central fibrosis surrounded by nests and tumor glands. Lung parenchyma is observed in the upper left and upper right corner (final magnification, x100).

setting, Palbociclib was paired with Fulvestrant vs. Fulvestrant alone in patients with metastatic hormone positive HER2 negative breast cancer who had progressed on prior endocrine therapy in the PALOMA III randomized phase III trial (49). The study also included pre and perimenopausal females who were required to take Goserelin (49). The combination of Palbociclib and Fulvestrant produced a significant 9.2 month progression free survival compared with 3.8 in the Fulvestrant and placebo arm (49). Abemaciclib is an inhibitor of CDK4 and CDK6 and in enzymatic assays is 14 times more potent against CDK4/cyclin D1 than CDK6/cyclin D3 (50).

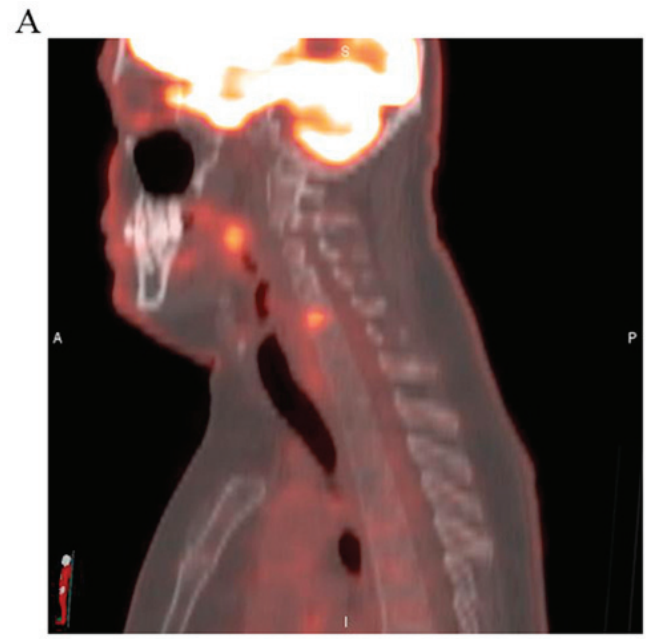

B

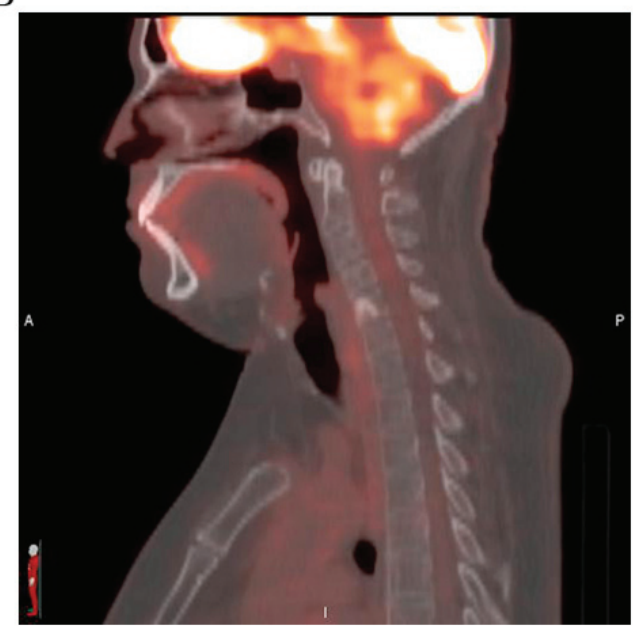

Figure 3. Baseline PET CT scans. (A) Sagittal view demonstrating metastatic disease to the 5 th vertebral body of the cervical spine. (B) Post treatment PET CT demonstrating resolution of FDG activity involving the 5th vertebral body of the cervical spine with overlying sclerosis.

Fujiwara et al (51) conducted a phase 1 study of single-agent Abemaciclib in Japanese patients with advanced metastatic solid tumors where 5/12 (41.6\%) patients were males. They concluded that single agent Abemaciclib demonstrated antitumor activity as a single agent and had an acceptable safety profile (51). In another phase I study, Abemaciclib as a single agent demonstrated antitumor activity in patients with several cancers with an ORR of $26 \%$ in patients with hormone refractory hormone positive metastatic breast cancer (52). Based on the single agent activity observed with Abemaciclib, the phase II MONARCH 1 study was launched (53). In this open label phase II single arm trial, women with hormone positive HER2 negative metastatic breast cancer who had progressed on or after prior endocrine therapy and had 1 or 2 prior chemotherapy regimens in the metastatic setting were enrolled (53). In this study patients who received single agent administered on a continuous schedule had an overall response rate of $19.7 \%$ with a median progression free survival of 6 months (53). Based on the results of MONARCH-I, the U.S. Food and Drug Administration approved Abemaciclib to be used alone to treat women and men diagnosed with hormone positive HER2 negative metastatic breast cancer that 
has progressed after hormone therapy and prior chemotherapy in the metastatic setting. Abemaciclib was also studied in the randomized phase III trial MONARCH 2, where Abemaciclib and Fulvestrant vs. Abemaciclib and placebo were studied in patients with hormone positive HER2 negative metastatic breast cancer who had progressed on prior endocrine therapy (54). The combination of Abemaciclib and Fulvestrant yielded a significantly improved PFS of 16.4 months compared with 9.3 months in the Fulvestrant and Placebo arm (54). Data regarding treatment responses to CDK 4/6 inhibitors in males is extremely limited. The first reported response in males was demonstrated in 2016 by S. Sorcher where a male with metastatic breast cancer achieved a partial response to Palbocliclib and Letrozole in the fifth line setting (55). The second known report by Castrellon et al (56) demonstrated a case of a male with metastatic breast cancer to lung and bone who achieved partial response to CDK 4/6 therapy with Palbociclib and Fulvestrant. Here we report the first male patient with metastatic breast cancer to achieve complete remission on a CDK 4/6 inhibitor. Given the lack of randomized controlled trials in male breast cancer treatment decisions are often extrapolated from data derived from female breast cancer trials. The standard of care for females with metastatic hormone positive HER2 negative metastatic breast cancer who progress on endocrine therapy is treatment with CDK 4/6 inhibitor with Fulvestrant. Our patient was treated as per MONARCH-II protocol given the significant benefit of the addition of Abemaciclib to Fulvestrant compared with Fulvestrant alone (54). Furthermore, Abemaciclib is the only CDK 4/6 inhibitor with an FDA approval in males and it has been previously studied in male cancer patients $(51,52)$. It should be noted however among the three FDA approved CDK 4/6 inhibitors (Abemaciclib, Palbociclib, Ribociclib) no head to head trials have been performed therefore no superior agent has been identified in cancer patients. The relative favorable side effect profile and response seen in this patient utilizing the combination of Fulvestrant, Abemaciclib and Lupron seems encouraging and further reports of CDK4/6 drug combinations may show responses. Identification of predictive biomarkers of response to CDK inhibitors represents one of the most important clinical areas of interest as CDK inhibitors have become the accepted first line treatment in metastatic hormone receptor positive HER2 negative breast cancer. Despite the excellent clinical advancement afforded by CDK inhibition a significant percent $(20 \%)$ of patients will not respond to CDK inhibition. Therefore identification of predictive biomarkers of response to CDK inhibition is prudent. Studies are slowly emerging in this field. Gong et al (57) analyzed the sensitivity of 560 cell lines to the selective CDK4/6 inhibitor abemaciclib and they found that cell lines with genomic features of D-cyclin activating features are particularly sensitive. Clinically however no reproducible predictive biomarker has emerged. For example in a phase II study using Palbociclib as a single agent in advanced breast cancer assessed progression free survival and $\mathrm{Rb}$ expression, KI-67, p16 loss, and CCND1 amplification. In this study there was no association between these biomarkers and response to therapy (58). Several studies are ongoing to elucidate potential predictive biomarkers. If more clinicopathologic and predicitive biomarker data could be accumulated on CDK 4/6 drug combinations in males with metastatic hormone positive male breast cancer this would help facilitate clinicians in selecting optimal therapeutic algorithms for individual males with breast cancer.

\section{Acknowledgements}

Not applicable.

\section{Funding}

No funding was received.

\section{Availability of data and materials}

All data generated or analyzed during the present study are included in this published article.

\section{Authors' contributions}

DH provided clinical management for the patient and developed their treatment protocol. DH also conceived the present study, wrote the manuscript, reviewed the treatment of stage IV male breast cancer and CDK 4/6 inhibitors for use in breast cancer, and supervised the study. SJ clinically treated the patient, and partially wrote and revised the manuscript. JS assembled pathological images and partially wrote the manuscript. RV assembled radiographic images and partially wrote the manuscript. RA wrote, critically revised and approved the manuscript, and developed the treatment protocol. All authors read and approved the final manuscript.

\section{Ethics approval and consent to participate}

The present case report was reviewed and approved by the Ethics Committee of the Cancer Treatment Centers of America.

\section{Patient consent for publication}

The patient verbalized consent for the publication of their information in a medical journal, which was documented in the medical record of the patient.

\section{Competing interests}

The authors declare that they have no competing interests.

\section{References}

1. Siegel RL, Miller KD and Jemal A: Cancer Statistics, 2017. CA Cancer J Clin 67: 7-30, 2017.

2. Anderson WF, Althuis MD, Brinton LA and Devesa SS: Is male breast cancer similar or different than female breast cancer? Breast Cancer Res Treat 83: 77-86, 2004.

3. Thomas DB: Breast cancer in men. Epidemiol Rev 15: 220-231, 1993.

4. O'Malley CD, Prehn AW, Shema SJ and Glaser SL: Racial/ethnic differences in survival rates in a population-based series of men with breast carcinoma. Cancer 94: 2836-2843, 2002.

5. Giordano SH, Buzdar AU and Hortobagyi GN: Breast cancer in men. Ann Intern Med 137: 678-687, 2002.

6. Cutuli B, Lacroze M, Dilhuydy JM, Velten M, De Lafontan B, Marchal C, Resbeut M, Graic Y, Campana F and MonchoBernier V: Male breast cancer: Results of the treatments and prognostic factors in 397 cases. Eur J Cancer 31A: 1960-1964, 1995. 
7. Mabuchi K, Bross DS and Kessler II: Risk factors for male breast cancer. J Natl Cancer Inst 74: 371-375, 1985.

8. Nahleh ZA, Srikantiah R, Safa M, Jazieh AR, Muhleman A and Komrokji R: Male breast cancer in the veterans affairs population: A comparative analysis. Cancer 109: 1471-1477, 2007.

9. Giordano SH, Cohen DS, Buzdar AU, Perkins G and Hortobagyi GN: Breast carcinoma in men: A population-based study. Cancer 101: 51-57, 2004

10. Ferzoco RM and Ruddy KJ: The epidemiology of male breast cancer. Curr Oncol Rep 18: 1, 2016.

11. Ewertz M, Holmberg L, Tretli S, Pedersen BV and Kristensen A Risk factors for male breast cancer-a case-control study from scandinavia. Acta Oncol 40: 467-471, 2001

12. Rosenblatt KA, Thomas DB, McTiernan A, Austin MA, Stalsberg H, Stemhagen A, Thompson WD, Curnen MG, Satariano W and Austin DF: Breast cancer in men Aspects of familial aggregation. J Natl Cancer Inst 83: 849-854, 1991.

13. Casagrande JT, Hanisch R, Pike MC, Ross RK, Brown JB and Henderson BE: A case-control study of male breast cancer. Cancer Res 48: 1326-1330, 1988.

14. Basham VM, Lipscombe JM, Ward JM, Gayther SA, Ponder BA, Easton DF and Pharoah PD: BRCA1 and BRCA2 mutations in a population-based study of male breast cancer. Breast Cancer Res BCR 4: R2, 2002

15. Couch FJ, Farid LM, DeShano ML, Tavtigian SV, Calzone K Campeau L, Peng Y, Bogden B, Chen Q, Neuhausen S, et al: BRCA2 germline mutations in male breast cancer cases and breast cancer families. Nat Genet 13: 123-125, 1996.

16. Friedman LS, Gayther SA, Kurosaki T, Gordon D, Noble B, Casey G, Ponder BA and Anton-Culver H: Mutation analysis of BRCA1 and BRCA2 in a male breast cancer population. Am J Hum Genet 60: 313-319, 1997.

17. Ottini L, Masala G, D'Amico C, Mancini B, Saieva C, Aceto G, Gestri D, Vezzosi V, Falchetti M, De Marco M, et al: BRCA and BRCA2 mutation status and tumor characteristics in male breast cancer: A population-based study in italy. Cancer Res 63 : 342-347, 2003

18. Sverdlov RS, Barshack I, Bar Sade RB, Baruch RG, Hirsh-Yehezkel G, Dagan E, Feinmesser M, Figer A and Friedman E: Genetic analyses of male breast cancer in israel. Genet Test 4: 313-327, 2000.

19. Ding YC, Steele L, Kuan CJ, Greilac S and Neuhausen SL: Mutations in BRCA2 and PALB2 in male breast cancer cases from the United States. Breast Cancer Res Treat 126: 771-778, 2011.

20. Silvestri V, Rizzolo P, Zanna I, Falchetti M, Masala G, Bianchi S, Papi L, Giannini G, Palli D and Ottini L: PALB2 mutations in male breast cancer: A population-based study in central italy. Breast Cancer Res Treat 122: 299-301, 2010.

21. Boyd J, Rhei E, Federici MG, Borgen PI, Watson P, Franklin B, Karr B, Lynch J, Lemon SJ and Lynch HT: Male breast cancer in the hereditary nonpolyposis colorectal cancer syndrome. Breast Cancer Res Treat 53: 87-91, 1999.

22. Fry DW, Harvey PJ, Keller PR, Elliott WL, Meade M, Trachet E, Albassam M, Zheng X, Leopold WR, Pryer NK and Toogood PL: Specific inhibition of cyclin-dependent kinase 4/6 by PD 0332991 and associated antitumor activity in human tumor xenografts. Mol Cancer Ther 3: 1427-1438, 2004.

23. Cardoso F, Bartlett JMS, Slaets L, van Deurzen CHM, van Leeuwen-Stok E, Porter P, Linderholm B, Hedenfalk I, Schröder C, Martens J, et al: Characterization of male breast cancer: Results of the EORTC 10085/TBCRC/BIG/NABCG international male breast cancer program. Ann Oncol 29: 405-417, 2018

24. Cardoso F, Costa A, Senkus E, Aapro M, André F, Barrios CH, Bergh J, Bhattacharyya G, Biganzoli L, Cardoso MJ, et al: 3rd ESO-ESMO international consensus guidelines for advanced breast cancer (ABC 3). Ann Oncol 28: 16-23, 2017.

25. Sharif MA, Mamoon N, Arif A and Khadim MT: Histological and immuno-histochemical study of male breast carcinoma in northern Pakistan. J Pak Med Assoc 59: 67-71, 2009.

26. Fox SB, Rogers S, Day CA and Underwood JC: Oestrogen receptor and epidermal growth factor receptor expression in male breast carcinoma. J Pathol 166: 13-18, 1992.

27. Arslan UY, Oksüzoğlu B, Ozdemir N, Aksoy S, Alkıș N, Gök A, Kaplan MA, Gümüs M, Berk V, Uncu D, et al: Outcome of non-metastatic male breast cancer: 118 patients. Med Oncol 29: $554-560,2012$
28. Moore J, Friedman MI, Gansler T, Gramlich TL, Derose PB, Hunt D and Cohen C: Prognostic indicators in male breast carcinoma. Breast J 4: 261-269, 1998.

29. Leach IH, Ellis IO and Elston CW: C-erb-B-2 expression in male breast carcinoma. J Clin Pathol 45: 942, 1992.

30. Willsher PC, Leach IH, Ellis IO, Bell JA, Elston CW, Bourke JB, Blamey RW and Robertson JF: Male breast cancer: Pathological and immunohistochemical features. Anticancer Res 17: $2335-2338,1997$

31. Giordano SH: A review of the diagnosis and management of male breast cancer. Oncologist 10: 471-479, 2005.

32. Gradishar WJ, Anderson BO, Balassanian R, Blair SL, Burstein HJ, Cyr A, Elias AD, Farrar WB, Forero A, Giordano SH, et al: Invasive breast cancer version 1.2016, NCCN clinical practice guidelines in oncology. J Natl Compr Canc Netw 14: 324-354, 2016

33. White J, Kearins O, Dodwell D, Horgan K, Hanby AM and Speirs V: Male breast carcinoma: Increased awareness needed. Breast Cancer Res 13: 219, 2011

34. Labrie F, Dupont A, Belanger A, Lacourcière Y, Béland L, Cusan L and Lachance R: Complete response to combination therapy with an LHRH agonist and flutamide in metastatic male breast cancer: A case report. Clin Invest Med 13: 275-278, 1990.

35. Lopez M, Natali M, Di Lauro L, Vici P, Pignatti F and Carpano S Combined treatment with buserelin and cyproterone acetate in metastatic male breast cancer. Cancer 72: 502-505, 1993.

36. Doberauer C, Niederle N and Schmidt CG: Advanced male breast cancer treatment with the LH-RH analogue buserelin alone or in combination with the antiandrogen flutamide. Cancer 62 : 474-478, 1988

37. Zagouri F, Sergentanis TN, Azim HA Jr, Chrysikos D, Dimopoulos MA and Psaltopoulou T: Aromatase inhibitors in male breast cancer: A pooled analysis. Breast Cancer Res Treat 151: 141-147, 2015 .

38. Zagouri F, Sergentanis TN, Chrysikos D, Dimopoulos MA and Psaltopoulou T: Fulvestrant and male breast cancer: A pooled analysis. Breast Cancer Res Treat 149: 269-275, 2015.

39. Lumachi F, Luisetto G, Basso SM and Camozzi V: Endocrine therapy of breast cancer. Curr Med Chem 18: 513-522, 2011.

40. Finn RS, Aleshin A and Slamon DJ: Targeting the cyclin-dependent kinases (CDK) 4/6 in estrogen receptor-positive breast cancers. Breast Cancer Res 18: 17, 2016.

41. Lundberg AS and Weinberg RA: Functional inactivation of the retinoblastoma protein requires sequential modification by at least two distinct cyclin-cdk complexes. Mol Cell Biol 18: 753-761, 1998.

42. Malumbres M: Cyclin-dependent kinases. Genome Biol 15: 122, 2014.

43. Gelbert LM, Cai S, Lin X, Sanchez-Martinez C, Del Prado M, Lallena MJ, Torres R, Ajamie RT, Wishart GN, Flack RS, et al: Preclinical characterization of the CDK4/6 inhibitor LY2835219: In vivo cell cycle-dependent/independent anti-tumor activities alone/in combination with gemcitabine. Invest New Drugs 32: 825-837, 2014.

44. Puyol M, Martin A, Dubus P, Mulero F, Pizcueta P, Khan G, Guerra C, Santamaria D and Barbacid M: A synthetic lethal interaction between K-Ras oncogenes and Cdk4 unveils a therapeutic strategy for non-small cell lung carcinoma. Cancer Cell 18: 63-73, 2010

45. Baker SJ and Reddy EP: CDK4: A key player in the cell cycle, development, and cancer. Genes Cancer 3: 658-669, 2012

46. Dean JL, McClendon AK, Hickey TE, Butler LM, Tilley WD, Witkiewicz AK and Knudsen ES: Therapeutic response to CDK4/6 inhibition in breast cancer defined by ex vivo analysis of human tumors. Cell Cycle 11: 2756-2761, 2012.

47. Finn RS, Crown JP, Lang I, Boer K, Bondarenko IM, Kulyk SO, Ettl J, Patel R, Pinter T, Schmidt M, et al: The cyclin-dependent kinase 4/6 inhibitor palbociclib in combination with letrozole versus letrozole alone as first-line treatment of estrogen receptor-positive, HER2-negative, advanced breast cancer (PALOMA-1/TRIO-18): A randomized phase 2 study. Lancet Oncol 16: 25-35, 2015

48. Finn RS, Martin M, Rugo HS, Jones SE, Im SA, Gelmon KA, Harbeck N, Lipatov ON, Walshe JM and Walshe JM: PALOMA-2: Primary results from a phase III trial of palbociclib (P) with letrozole $(\mathrm{L})$ compared with letrozole alone in postmenopausal women with $\mathrm{ER}^{+} / \mathrm{HER} 2$-advanced breast cancer. J Clin Oncol: May 11, 2017 (Epub ahead of print). doi: 10.1200/ JCO.2016.34.15 suppl.507. 
49. Turner NC, Ro J, Andre F, Loi S, Verma S, Harbeck HI, Loibl S, Bartlett $\mathrm{CH}$, Zhang $\mathrm{K}$ and Giorgetti $\mathrm{C}$, et al: PALOMA3: A double-blind, phase III trial of fulvestrant with or without palbociclib in pre- and post-menopausal women with hormone receptor-positive, HER2-negative metastatic breast cancer that progressed on prior endocrine therapy. J Clin Oncol: Jan 31, 2017 (Epub ahead of print). doi: 10.1200/jco.2015.33.18_suppl.lba502.

50. Lallena MJ, Boehnke K, Torres R, Hermoso A, Amat J, Calsina B, De Dios A, Buchanan S, Du J, Beckmann RP, et al: In-vitro characterization of Abemaciclib pharmacology in $\mathrm{ER}^{+}$breast cancer cell lines. Presented at Proceedings of the 106th Annual Meeting of the American Association for Cancer Research (AACR) Congress. (abstract 3101), 2015. doi: 10.1158/1538-7445. AM2015-3101.

51. Fujiwara Y, Tamura K, Kondo S, Tanabe Y, Iwasa S, Shimomura A, Kitano S, Ogasawara K, Turner PK and Mori J: Phase 1 study of abemaciclib, an inhibitor of CDK 4 and 6, as single agent for Japanese patients with advanced cancer. Cancer Chemother Pharmacol 78: 281-288, 2016.

52. Patnaik A, Tolaney SM, Tolcher AW, Goldman JW, Gandhi L, Papadopoulos KP, Beeram M, Rasco DW, Hilton JF, Nasir A, et al: Efficacy and safety of abemaciclib, an inhibitor of CDK4 and CDK6, for patients with breast cancer, non-small cell lung cancer, and other solid tumors. Cancer Discov 6: 740-753, 2016.

53. Dickler MN, Tolaney SM, Rugo HS, Cortés J, Diéras V, Patt D, Wildiers H, Hudis CA, O'Shaughnessy J, Zamora E, et al: MONARCH 1, a phase II study of abemaciclib, a CDK4 and CDK6 inhibitor, as a single agent, in patients with refractory $\mathrm{HR}^{+} / \mathrm{HER} 2-$ metastatic breast cancer. Clin Cancer Res 23 . 5218-5224, 2018.
54. Sledge GW Jr, Toi M, Neven P, Sohn J, Inoue K, Pivot $X$, Burdaeva O, Okera M, Masuda N, Kaufman PA, et al: Monarch 2: Abemaciclib in combination with fulvestrant in women with $\mathrm{HR}^{+} / \mathrm{HER} 2{ }^{-}$advanced breast cancer who had progressed while receiving endocrine therapy. J Clin Oncol 1: 2875-2884, 2017.

55. Sorscher S: A first case of male breast cancer responding to combined aromatase inhibitor/palbociclib therapy. Int J Cancer Clin Res: Oct 19, 2016 (Epub ahead of print).

56. Castrellon AB, Nguyen SM, Milillo Naraine AM, Velez M and Raez LE: Initial response to therapy with fulvestrant and cyclin-dependent kinase 4/6 inhibitor in a male with stage IV breast cancer. Mathews J Cancer Sci: Mar 1, 2017 (Epub ahead of print).

57. Gong X, Litchfield LM, Webster Y, Chio LC, Wong SS, Stewart TR, Dowless M, Dempsey J, Zeng Y, Torres R, et al: Genomic aberrations that activate D-type cyclins are associated with enhanced sensitivity to the CDK4 and CDK6 inhibitor abemaciclib. Cancer Cell 32: 761-776, 2017.

58. DeMichele A, Clark AS, Tan KS, Heitjan DF, Gramlich K, Gallagher M, Lal P, Feldman M, Zhang P, Colameco C, et al: CDK 4/6 inhibitor palbociclib (PD0332991) in $\mathrm{Rb}^{+}$advanced breast cancer: Phase II activity, safety, and predictive biomarker assessment. Clin Cancer Res 21: 995-1001, 2015.

This work is licensed under a Creative Commons Attribution-NonCommercial-NoDerivatives 4.0 International (CC BY-NC-ND 4.0) License. 